\title{
The Homonymic Chain Model as a Tool for Multiple Sense Analysis
}

\author{
Juliet Oppong-Asare \\ Department of Modern Languages, Kwame Nkrumah University of Science and Technology, Kumasi, Ghana \\ Charles Marfo \\ Department of Modern Languages, Kwame Nkrumah University of Science and Technology, Kumasi, Ghana
}

\begin{abstract}
Many scholars - e.g. Glover (2005), Sekyi-Baidoo (2006) and Falkum (2010) - have expressed some concerns about Word Sense Multiplicity (WSM), which explains multiple meanings as part of a word. In other words, WSM is an integral part of any natural language including Akan on which this paper concentrates. As Agyekum (2002; 2005) and Levin (1993) observe, with WSM, users and researchers of language dwell on a particular sense of a word deeming it as an underlying representation of all other senses. In this paper, however, from the perspective of the homonymic and polysemic nature of a word, we seek to explore the Homonymic Chain Model (Oppong-Asare, 2012) as a tool for expressing the multiple meanings words in languages in descriptive terms. The model attempts to simplify the understanding of the various meanings of a word by conceptualizing its diverse senses. As will also be exhibited pictorially, the Homonymic Chain Model (HCM) also explains that a particular word may have two or more distinct meanings and each of the meanings may also have other related senses. As part of our conclusion, we contend among others that apart from aiding students and language learners to recognize and comprehend different senses of a word more clearly, HCM could also facilitate the work of translators working with Akan.
\end{abstract}

\section{Indexing terms/Keywords}

Homonymy, polysemy, lexical ambiguity, word sense multiplicity

\section{Academic Discipline And Sub-Disciplines}

Semantics; Analytical framework; Modelling;

\section{SUBJECT CLASSIFICATION}

Theoretical linguistics; Descriptive linguistics

\section{TYPE (METHOD/APPROACH)}

Mixed: Quasi-theoretical and Descriptive Analysis

\section{INTRODUCTION}

Words with multiple meanings are part of any natural language, including Akan (specifically, Asante-Twi) on which this paper is, and this underscores the idea of Word Sense Multiplicity (WSM). WSM often manifests when the lexeme is not positioned within a (syntactic) context; i.e. when it is in isolation. Also, it becomes a problem when it leaves a huge gap between interlocutors; i.e. in a situation where a speaker's intention is misinterpreted by a listener. This is a case of lexical ambiguity, which could even arise in contexts. Let us observe that Akan belongs to the Kwa group of the Niger-Congo language family and Asante-Twi is one of the several varieties of it. Some other varieties that have attained literary status like Asante-Twi are Fante and Akuapim-Twi.

Aronorff and Fudeman (2005) see polysemy (and homonymy) as the main causes of WSM because individual lexemes are highly diverse in meaning. Parent (2009) gives a scenario in this regard in which a film major student who needed to shoot footage as part of his film making assignment entered an office and said 'I want to shoot somebody.' He was misunderstood by some workers at the scene and, as a result, one sneakily called the security guards. In trying to understand the misunderstanding, one may quickly conclude that the student used the verb shoot wrongly. However, the question we need to ask is whether 'shooting someone with a gun' is the basic meaning or not. To Parent (2009), there is some level of semantics in which 'shooting' with a gun and 'shooting' with a camera are very similar procedures. While the outcomes are undeniably different, both actions require aiming a pre-loaded, constructed apparatus at someone or something and pressing a control, after which the 'shooting' action is instantly completed. Parent (2009), therefore, sees the student's error as entirely pragmatic rather than semantic or syntactic. Following Parent, we contend that what the student failed to do was modulating the verb's context appropriately for the non-film environment he found himself in. He could have been spared if he had put the sentence in this way: 'I need to shoot some footage of people in this scene for my film project'. Better still, he could have entered the office with his camera (as the instrument for the action) as he made his request. This could have enabled understanding of what he actually meant. However, the situation would have been different among his 'film' colleagues even in the present environment.

As indicated earlier, Parent's example is a real semantic problem that can occur in every language. Brown (2008) admits this by suggestion that the semantic ambiguity of lexical forms is pervasive in almost all languages and that many, if not most, words have multiple meanings. Despite the presence of WSM, how human beings store and access these meanings is an open question which is, do we have a separate representation in our mental lexicon for each sense of a word, or do we store only one very generalized or core meaning for each word? Many researchers have investigated this question of

\footnotetext{
1146 | P a g e

A ugust 2016
} 
multiple sense ambiguity with lexical assessment tasks. Responses sometimes are thought to indicate how easily a subject has accessed the word. To address this phenomenon, studies of this kind have to be carried out to clarify the various senses which are stealthily situated in words. Many natural languages have complex features which make analysis of aspects of any one of them complicated. In this work, we attempt to mitigate the complications in WSM by using a model; i.e. Homonymic Chain Model (Oppong-Asare, 2012). We contend that using models to analyze any aspect of language do not only simplify the concepts they describe but, also, appeal to the perception of readers with their pictorial representation. Accordingly, later in our discussions we will highlight how various models have been used in language analysis.

\section{HOMONYMY AND POLYSEMY IN LEXICAL SEMANTIC THEORY}

Lexical semantics studies how and what words of a language denote. In other words, it looks at the meaning makeup of a word (Pustejovsky, 1995; Sekyi-Baidoo, 2002). One issue that is of a greater concern in lexical semantics is whether the meaning of a lexical unit is instituted by looking at its environment in the semantic net (i.e. the other words it collocates with within natural sentences) or if the meaning is already locally contained in the lexical unit. Another area that is explored in a theory of lexical semantics is the mapping of words to concepts. Under this, issues like lexical or sense relations (defined as patterns of association that exist between lexical items in a language) are discussed. Three types of sense relations are considered in this paper; i.e. homonymy, polysemy and synonymy.

Homonymy refers to a situation in which two or more words have the same physical manifestation but have different or unrelated senses or meaning. This means that the words involved are spelt and pronounced in the same way, but considering the context they find themselves, they do not relate in meaning. In the dictionaries, homonyms are listed separately though they have the same spellings. Polysemy also refers to a situation where single words with multiple meanings relate. These senses are considered polysemes because they share the characteristics of the core meaning. There is a situation where by two or more words are closely related in terms of their meaning but not (necessarily) identical in form; these words are known as synonyms; if possible, synonyms of the various homonyms will be highlighted to streamline their unrelatedness.

\section{ANALYTICAL FRAMEWORK: OVERVIEW OF MODELS}

According to the Business Dictionary (see http://www.businessdictionary.com/definition/model.html; retrieved on December 14, 2015), a model can be explained as a graphical, mathematical (symbolic), physical or verbal representation or simplified version of a concept, phenomenon, relationship, structure, system or an aspect of the real world. According to Matthews (2007: 248), it is "a pattern that may be followed in describing the structures of particular languages". By using our knowledge of simpler things, models generally allow us to explore complex things that we could not have been able to understand well. Most concepts, phenomena and structures are so complicated because of their numerous parts. They are also complex because these (complex) parts have condensed interconnections. Thus, for them to be wholly comprehended, a model must be used to capture the features that are of primary importance. Indeed, once a model is met with supporting evidence, it can be used confidently to make reliable predictions about the phenomenon it represents.

The methods chosen to model a given system depend mostly on the qualitative and quantitative features of data available to construct the model and on the question(s) that is asked. Theories that gain recognition in a discipline shape the field and help define the scope of practice. This can extensively be adopted in other disciplines to analyze structures that share similar traits as the original beneficiary of the model, for instance, Frege's principles of context and compositionality in his Die Grundlagen der Arithmetik 'The Foundations of Arithmetic' of 1884. Although these principles were originally proposed to investigate the philosophical foundations of arithmetic, today, they are also relevant frameworks in semantic analysis. As presented in Fig 1 below, a model could encompass theories, concepts and principles. One could therefore observe a state of simplification or a summary of a much broader idea in theory, concept and principles.

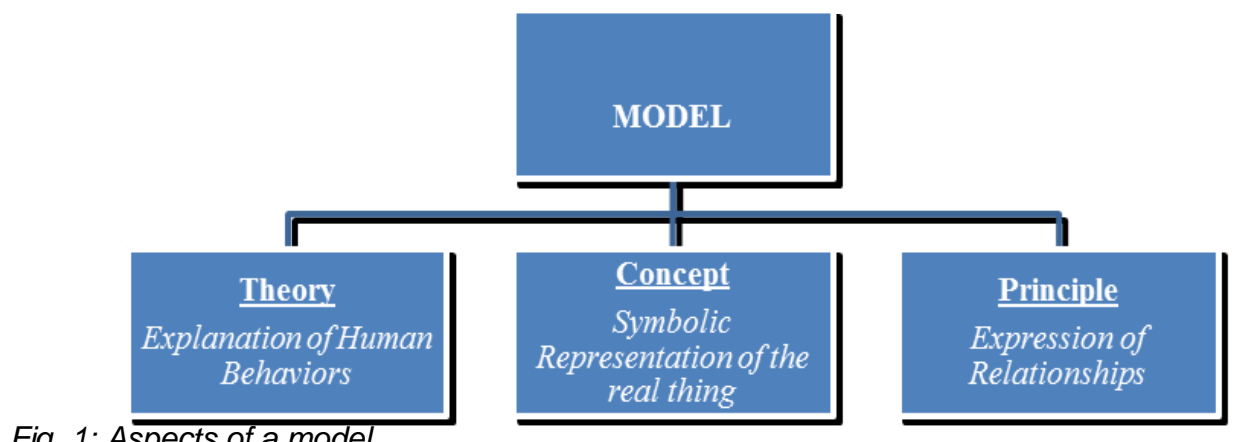

Fig. 1: Aspects of a model

Following McMillan \& Schumacher (1984) and Garrison (2002) theories, concepts and principles are systematic. On theory in particular, Moore (1991: 2) explains that it is '... the reduction of our knowledge to the basic ideas presented in a way that shows their underlying patterns and relationships'. This tends to capture the underlying significance of a model as something that ensures simplicity and compact ways to conveying information. Moore's position will, therefore, be 
extended to the description of our model, Homonymic Chain Model (HCM). In the first place, however, we will attempt to explain how HCM can be classified as a model and a linguistic one for that matter.

\section{SOME MODELS FROM OTHER DISCIPLINES AND LINGUISTICS}

As noted earlier, because of their compact ways to conveying information, models have been designed and used by many scholars in diverse areas of study for analyses. Indeed, the reasons are countless, including the fact that models also serve as a quick way for audience to visualize what one is saying. We can talk of graphs, bar and pie charts and formulas in mathematics as well as maps in geography. In psychology, for instance, we can cite how Pavlov (1927) and Skinner (1938) used model-based illustrations to buttress their Operant Conditioning and Classical Conditioning respectively. From sociological perspective, we can also make mention of Maslow $(1943 ; 1954)$ - i.e. Maslow's Hierarchy in the form of a pyramid - to explain how human needs can be ranked as Fig 2 below shows. Also, in the pure sciences, diagrams have been used to explain the processes of filtration, germination, fertilization, etc.

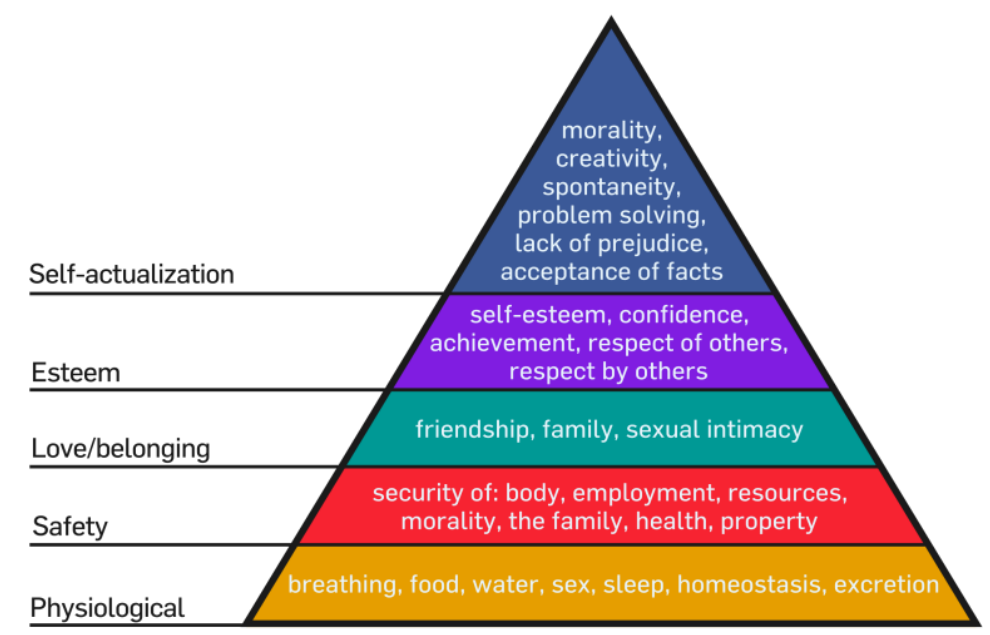

Fig. 2: Maslow's hierarchy of needs

In linguistics, many of such models have been designed to help conceptualize complex aspects of languages and to help the understanding of certain linguistic concepts. One of such models has been theorized as Lexical Functional Grammar (LFG).

LFG (e.g. Bresnan 2001) is a theoretical framework of linguistics, which is noted for its rules. LFG views language as having been made up of multiple dimensions of structure, each of which is represented as a distinct structure with its own rules, concepts, and form. The primary structures have been noted as the constituent structure (c-structure) and the functional structure (f-structure) and these reflect in the name of the theory. For detailed discussions and insight into these two structures of the theory and for that matter the theory itself, the reader is encouraged to consult appropriate literature; e.g. Bresnan (2001), Falk (2001), etc. However, in terms of modeling, the entire theory is made simple or simply captured with structures as seen in Figures (3a) and (3b) for the c-structure and the f-structure respectively.

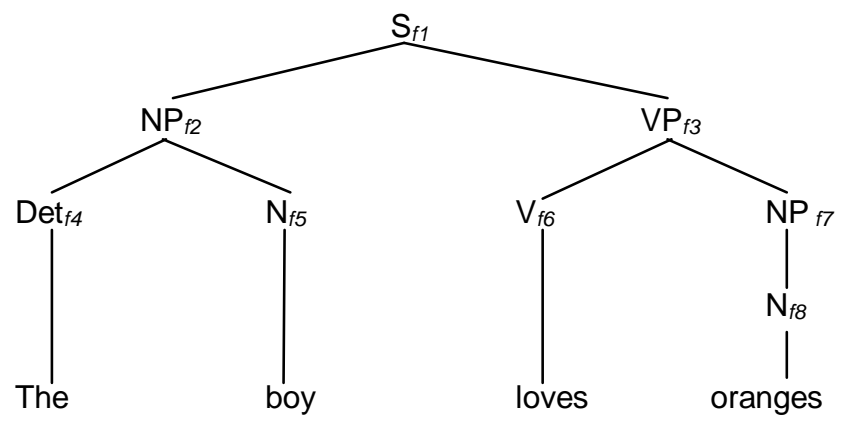

Fig. 3a: C-Structure

[PRED 'love'r(†SUBJ), (†OBJ)>

TENSE Pres. 
As seen above, the LFG structures above capture the valency and tense of the verb 'love'. Particularly in the F-Structure, it also captures the specific determiner and number of the subject NP, as well as the object NP. The C-Structure on the other hand shows the linear relations of the categories in the sentence; i.e. the subject precedes the verb and the object. Understanding these structures, and for the matter the LFG model, makes the entire theory easily comprehensible.

Another instance where a model is used to explain a linguistic concept is seen in Lehmann's parameters for grammaticalization. According to Lehmann, the primary feature of grammaticalization is loss in autonomy of the linguistic sign which, thereby, makes the transition from being a content word to being a functional word. Sarpong (2005: 9-10) outlines three aspects of linguistic autonomy. These three are defined by Lehmann (2002) as weight (i.e. each sign's distinctiveness), cohesion (i.e. the extent to which each sign contracts relations with other signs), and variability (i.e. the shiftability of the sign with respect to other signs). To Lehmann, grammaticalization is a process and he explains how this process occurs with a simple diagram as demonstrated as Figure 4 below and described therein.

\section{Stage}

I.

II
a.

b.

$\stackrel{V}{\downarrow} \stackrel{\mathrm{f}}{\downarrow}$

c.

III

a.

\section{Category}<smiles>CC(C)CPCP</smiles>

(V) $\quad P$

b.<smiles>N#CP</smiles>

$V \neq P$
The word occurs only as a verb.

The word occurs both as a verb and as an adposition but its impact as a verb is stronger

The co-verb-adposition stage

The word is considered an adposition than a verb.

The word occurs only as an adposition.

Underlying verb and adposition become homophones.

Fig. 4: Lehmann's (2002: 94) Parameters for Grammaticalization

From Fig 2, 3 and 4, one could see that models are very useful tools for conceptual analysis as we have pointed out earlier and, as could also be observed, they are especially useful in linguistics. In the rest of the paper, therefore, we present the structure of HCM and explain how it can be classified as a model by looking at its features and function.

\section{HCM AS A MODEL}

In the application of our subscribed Homonymic Chain Model (HCM), we employ a model as a tool for the analysis of words with multiple meanings. An earlier version of HCM (as a model) was designed and used by Oppong-Asare (2012) in analyzing the Akan verb $\mathbf{D I}$ to critically underscore its homonyms and polysemes in grammar. With the help of HCM, twelve lexemes of the verb DI were identified, which include 'to consume', 'to speak', 'to have sex', 'to be in a position', 'to perform an activity' and 'to spend'. It was also realized in Oppong-Asare (2012) that about ten of the identified lexemes/words are polysemous.

In its structure, the HCM is described as a four tier/level model and each tier exhibits an identifiable linguistic item (sense relation). This state is presented in Fig 5 below.

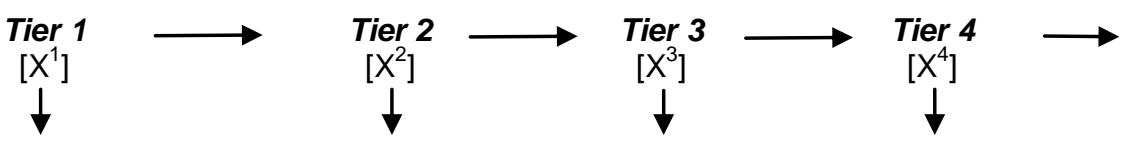


Form

(Homonymic)

Fig. 5: The HCM Model
Lexeme

(Denotative)
J o urna I

Variant

(Polysemic)
Context

(Contextual)

As could be followed from Fig 5, HCM explains as follows: Tier 1 ([X $\left.\left.\mathrm{X}^{1}\right]\right)$ is the level where the word is realized in isolation as a form. A form, according to Matthews (2007: 143) is a structure (of relation) among linguistic units considered in abstraction. With a same form and pronunciation, it is tempting to consider different forms as one same word. This then may be the reason for a single representation of all forms. From Oppong-Asare (2012)'s presentation of the HCM, Tier 1 $\left(\left[X^{1}\right]\right)$ contains the form /DI/, which can represent any of the twelve lexemes or words identified.

Tier $2\left(\left[\mathrm{X}^{2}\right]\right)$ is the level where all possible collocations have been taken into consideration and the denotative meanings that branch from Tier $1\left(\left[X^{1}\right]\right)$ have been identified. At this level, consideration is given to the company each form keeps (Firth 1956) in terms of the words each collocates with to give their distinctive meanings. A prototype meaning is then adopted to represent all the similar denotations. It is crucial to note that this prototype meaning is based on the common traits the individual denotations share. For instance, as noted earlier, $\boldsymbol{D I}$ can denote 'being in a queue' as in (1a), 'being in genealogical sequence' as in (1b), 'being in leadership' as in (1c), and 'to support one's view' as in (1d), all of which seem to capture an intrinsic concept of 'position' at Tier 2 ([X²]) of HCM.

\begin{tabular}{|c|c|c|c|}
\hline a. & $\begin{array}{l}\text { Me-di w'-akyi } \\
\text { 1sg.-eat 2sg.Poss-back } \\
\text { 'I am behind you'. }\end{array}$ & b. & $\begin{array}{l}\text { Kofi di Ama akyi } \\
\text { Kofi eat Ama back } \\
\text { 'Kofi comes after Ama (as siblings)' }\end{array}$ \\
\hline C. & $\begin{array}{l}\text { O-di panin } \\
\text { 3sg.-eat leader/elder } \\
\text { 'He is a leader'. }\end{array}$ & d. & $\begin{array}{l}\text { O-di ne ba akyi } \\
\text { 3sg.-eat Poss seed back } \\
\text { 'He supports his child'. }\end{array}$ \\
\hline
\end{tabular}

In other words, all the denotations in (1) are with the prototype term 'position' because a person's position, whether abstract or concrete, is seen in each instance. The word $\boldsymbol{d i}$ 'position' here then is a lexeme - DI - i.e. it carries a semantic interpretation and embodies a distinct cultural concept which is seen in the meaning it carries.

Tier $3\left(\left[X^{3}\right]\right)$ is the level where a lexeme exhibits its polysemes; i.e. various senses. Each related sense is seen here as a variant of the prototype sense (lexeme); that is the same denotation that is partially different based on the different cognitive usage. Tier $4\left(\left[\mathrm{X}^{4}\right]\right)$ is the last level and this is where each variant is expressed in the selected native language; i.e., each variant is situated in a context. As could be observed with the four different examples in (1), as many variants as examples as space may permit can be cited. The arrow after Tier 4 indicates that HCM gives room for extended meaning and glossing where there is the need.

Sometimes the language that data is drawn from may differ from the text language. There may therefore be the need to translate phrases or sentences to fit the text language. Similarly, a polyseme may have a figurative sense that would need considering. All these extra information will come after $\left[X^{4}\right]$; they can either be treated as an extension of Tier 4 ([ $\left.\left.X^{4}\right]\right)$ or a new tier can be created for that category.

\subsection{Componential Analysis of the Homonymic Chain Model}

The working three-termed model of this paper, 'Homonymic Chain Model', has been carefully put together on the bases of functional and structural representations. With the term 'Homonymic', we observe that a lexeme may or may not have polysemes. However, we also note that there is no polyseme that does not ultimately map to a homonym (a lexeme); i.e. polysemy cannot manifest without an expression of an affiliation to a homonym, hence our choice of the term 'Homonymic'. HCM is also described as a 'Chain' because it exhibits an interrelation between its four identified and described tiers; a continuum which is not broken within structure. Lastly, as noted by Matthews (2007: 248), a model can be described as 'a pattern that may be followed in describing the (structures) of particular languages' and that is how HCM could be described. Indeed, Oppong-Asare (2012) points out that HCM is a 'Model' because it was originally designed for the analysis of a specific form (i.e. di). After a critical consideration, however, we contend that HCM can be extended to the analysis of other words as its equivalent tabular form given in Fig 6 below suggests.

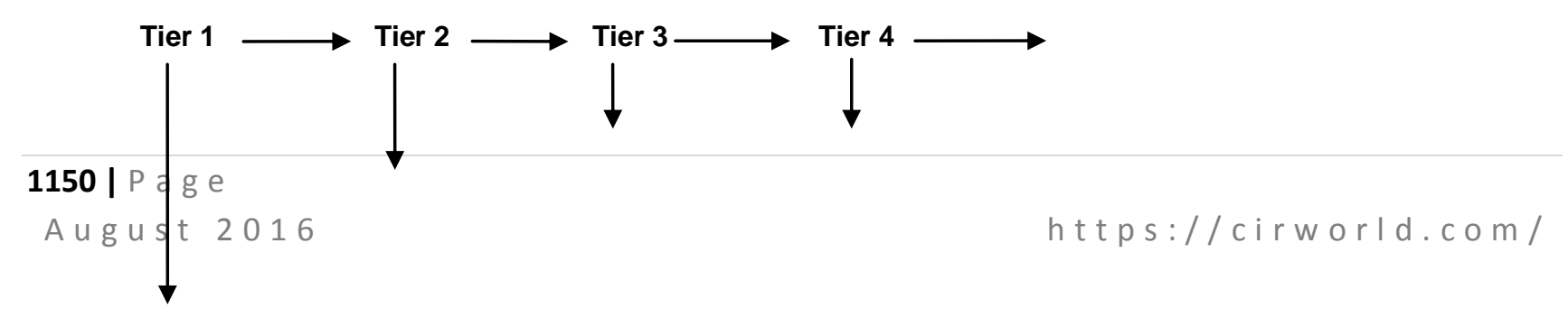




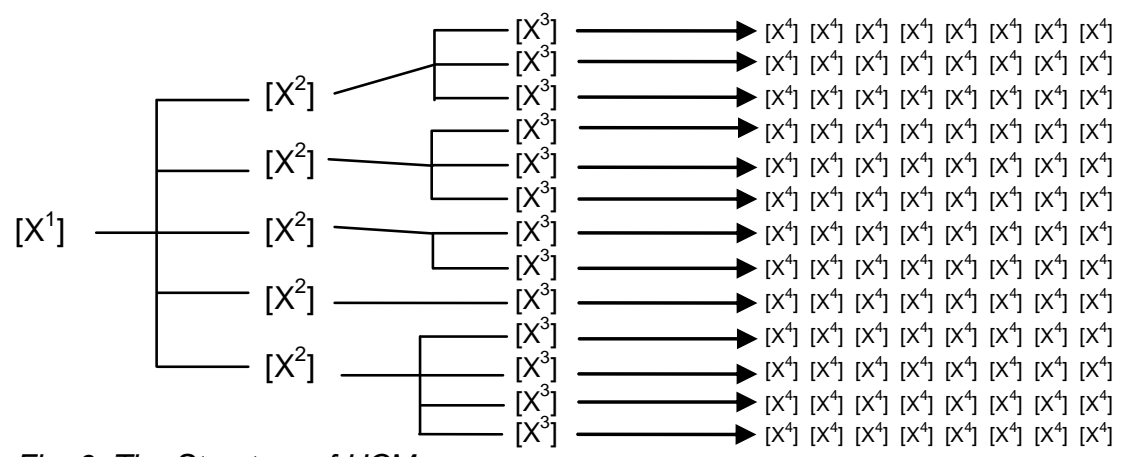

Fig. 6: The Structure of HCM

Secondly, as will be exemplified in Fig. 7 below, HCM simplifies the concepts of homonymy and polysemy and it is, thus, a model.

Going back to explaining Fig. 6 , Tier 1 , Tier 2 , Tier 3 and Tier 4 map to $\left[X^{1}\right],\left[X^{2}\right],\left[X^{3}\right]$ and $\left[X^{4}\right]$ respectively. This structure does not represent any particular word form as we seek to portend. As we have somehow touched on in the explanation of with Fig. 5, in reality, $\left[X^{1}\right]$ is represented by only one entity in most cases. This is because even the many senses (or meanings) of it all share the same form and pronunciation. Indeed, it is important to emphasize that, at [ $\left.X^{1}\right]$, there is no specific meaning and that is where the ambiguity is noticed. To do away with the ambiguity, we consider the company that one entity (i.e. that one word at $\left[X^{1}\right]$ ) keeps (Firth, 1956) or their collocation at Tier 4 (see Fig. 7). That is to say, an [ $\left.X^{1}\right]$ may have as many $\left[\mathrm{X}^{2}\right]$ as possible. As noted earlier and exemplified with some examples in (1), Oppong-Asare (2012) for instance recorded twelve $\left[X^{2}\right]$ entities of the verb di. The same applies to $\left[X^{3}\right]$ and $\left[X^{4}\right]$. It should be noted that it is a possibility that an $\left[\mathrm{X}^{2}\right]$ may or may not have an $\left[\mathrm{X}^{3}\right]$. To put it differently, a homonym may have as many polysemes as possible, but some may have no polysemes at all. Finally, any other information after Tier 4 is considered necessary and it is dependent on the relationship between the data language and text language.

\subsection{Application of HCM}

We have contended and observed that the basic function of the HCM is to analyze words with multiple senses. These words can either be content ones like nouns, verbs, adjectives and adverbs or grammatical words like prepositions, conjunctions, particles and interjections though content words are more likely to have multiple senses than grammatical words. In this section, we look into the verb $\mathrm{BU}$ in Akan through $\mathrm{HCM}$ analysis as presented in Fig. 7 below.

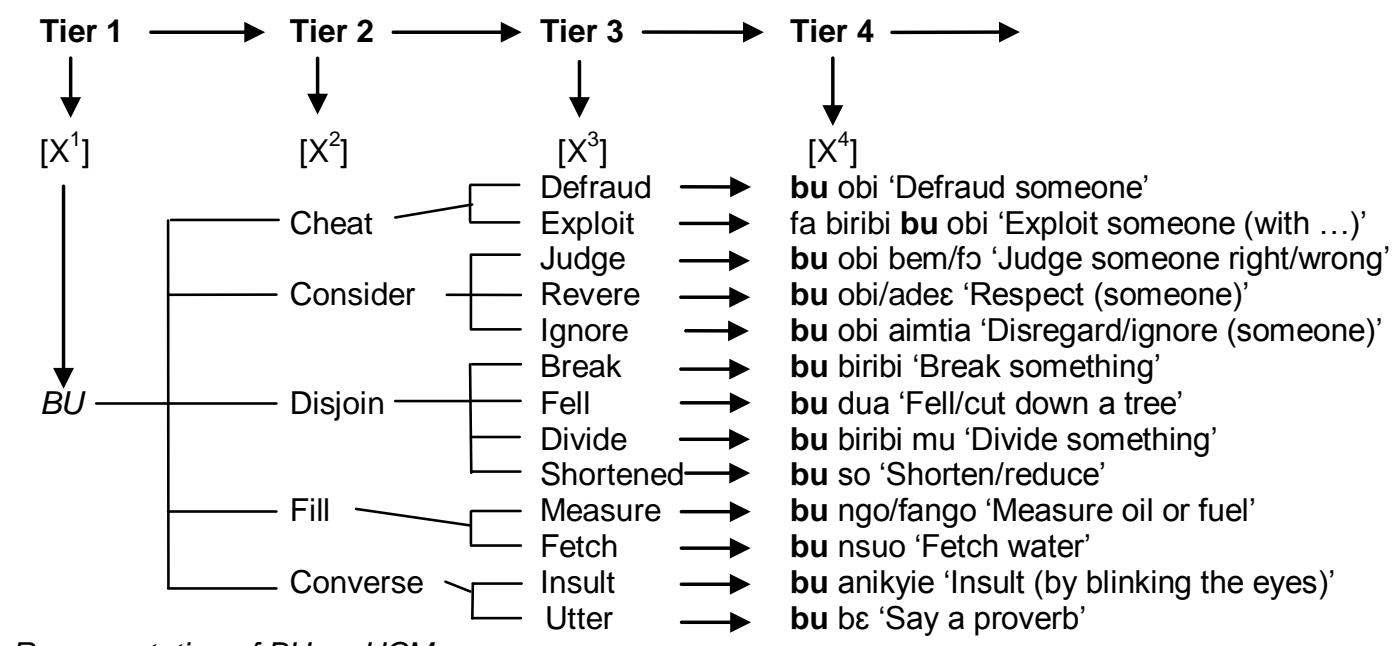

Fig. 7: Representation of BU on HCM

We can see from the HCM above that the verb $\boldsymbol{B} \boldsymbol{U}$ does not have a specific meaning at Tier 1 ([X $\left.\left.\mathrm{X}^{1}\right]\right)$. At this level, it is perceived as a (bare/indefinite verb) form whose referent(s) and reference(s) are not known. It, however, exhibits multiple senses or meanings at Tier 4 in particular; i.e. individual meanings become defined when the verb form collocates with other words. In other words, as was pointed out earlier, each sense or meaning evolves or could only be determined within a syntactic context; through the common form's collocation with other categories as could be seen in Tier 4 of Fig. 7. In the syntactic context, $\boldsymbol{B} \boldsymbol{U}$ has the structure of VP $\rightarrow$ V NP (NP/PostP).

We see from Tier 2 that $\boldsymbol{B U}$ has five (5) homonyms. It must however be explained that there could be other homonyms here in Akan but for the sake of space this paper has only attempted to concentrate the discussion on only these few at Tier $2\left(\left[X^{2}\right]\right)$. One way of proving the unrelatedness of the homonyms at Tier 2 is to consider their synonyms (if any) and 


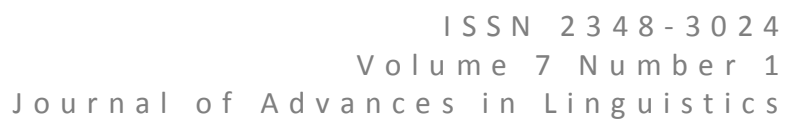

also consider their nominalization (forming nouns from each sense). For instance, 'to cheat' meaning of $\boldsymbol{B U}$ may have the phrasal verb bo apoo as in (2a) or the verb twa as in (2b) below as its synonyms.

$2 \quad$ a. Papa no bo-s (Kofi) apoo.

man Def. hit-PST ideophone

'The man cheated (Kofi)'.

b. $\quad$ Papa no de mpaboa a-bu /a-twa Kofi

man Def. use footwear PERF-cheat Kofi

'The man has cheated Kofi by selling him footwear at very high price'.

Also made evident in Fig. 7, is the fact that Tier $3\left(\left[\mathrm{X}^{3}\right]\right)$ of the HCM outlines polysemes of each identified homonym at Tier 2. Thus, for example, 'to cheat' evolves the senses of 'to defraud' and 'to exploit' as its polysemes. The two senses are related because, in both situations, someone takes advantage of another. Similarly, 'to consider' evolves 'to judge', 'to revere' and 'to ignore' as its polysemes and their relatedness lies in the fact that, one judges, reveres or ignores an entity based on how one considers that entity.

\section{Conclusion}

This paper has strived to explain that models are very important in the analyses of linguistic phenomena and aspects of natural languages. Particularly, the Homonymic Chain Model (HCM) has been used and has proven very useful in analyzing the multiple senses of the Akan verbs $\boldsymbol{B U}$, following Oppong-Asare's (2012) use of the model in the determination of the various senses of Akan verb DI. In this paper, HCM has aided us to identify the homonyms and polysemes of the verb form $\mathbf{B U}$. To highlight the significance of the $\mathrm{HCM}$, we can mention that all the tiers, which are interrelated in a continuum fashion, are functional and descriptive enough to explain some sense relations between words/forms.

As a model, the HCM records certain noticeable advantages which make it operative. First, it helps to simplify homonymy and polysemy as semantic concepts and its application with the word $\boldsymbol{B} \boldsymbol{U}$ attests to this fact. The pictorial representation of the various meanings relieves readers from cumbersome contents to be read. Secondly, the HCM tries to bridge the gap between semantics and pragmatics because most of the meanings of the verb discussed above (i.e. $B \boldsymbol{C}$ ) are based on context, that is, how they have been used in syntactic and other contexts. Third, the HCM can be used to analyze words from different classes like nouns, prepositions and the like. Also it can be useful in translation since translators can use it to outline the multiple meanings and functions of words to enhance appropriateness in the choice of corresponding words between source languages and receptor languages. Last but not the least, we can mention its flexibility, in that, entries on the HCM are not restrictive; it does not follow any particular order, say alphabetical order, frequent usage or number of polysemes. This underscores the easiness in analyzing words with multiple meaning.

\section{References}

1. Agyekum, K. (2002). Lexical polysemy and metaphorical extensions of Te 'hear' perception verb in Akan. Legon Journal of Humanities 13: 99-113.

2. Agyekum, K. (2005). Polysemy and metaphorical extensions of hunu 'vision' perception verb in Akan. Studies in the Languages of the Volta Basin 3: 147-162.

3. Aronoff, M. \& Fudeman, K. (2005). Fundamentals of Linguistics: What is morphology? Chichester: Blackwell Publishing Ltd.

4. Bresnan, J. (2001). Lexical-functional syntax. Oxford: Blackwell Publishers.

5. Brown, S. W. (2008). Polysemy in the mental lexicon. Colorado Research in Linguistics 21.2: 1-14.

6. Chomsky, N. (1957). Syntactic Structures. The Hague: Mouton.

7. Falk, Y. N. (2001). Lexical-Functional Grammar: An Introduction to Parallel Constraint-Based Syntax. Stanford: CSLI Publications.

8. Falkum, I. L. (2010). The Semantics and Pragmatics of Polysemy: A Relevance Theoretic Account. Unpublished PhD Dissertation, University College of London.

9. Firth, J. R. (1956). Descriptive linguistics and the study of English. In Frank R. Palmer (Ed.), Selected Papers of J.R. Firth (1952-59). London and Bloomington: Longman and Indiana University Press. Pp. 96-113.

10. Frege, G. (1953). Grundlagen der arithmetic. Translated by J.L. Austin as The foundations of Arithmetic. Oxford: Blackwell.

11. Garrison, J. (2002). Summing up our differences: A reply to Siegel. Journal of the Philosophy of Education 36.2 : 229-232

12. Glover, K. (2005). Polysemy: Methods and Materials, Models and Meanings. Unpublished M.A. Dissertation, University of Essex.

13. Goldsmith, J. A. (1990). Autosegmental and Metrical Phonology. Oxford: Blackwell.

14. Kaplan, R. M. \& Bresnan, J. (1982). Lexical functional grammar: A formal system for grammatical representation. In Joan Bresnan (Ed.), Mental Representation of Grammatical Relations. Cambridge, MA: The MIT Press. Pp.173-281.

15. Kouwenberg, J. N. C. (1997). Germination in the Akkadian verbs. Assen: K.Van Gorcum \& Co B.V.

16. Lehmann, C. (2002). Thoughts on Grammaticalization. Munich: LINCOM Europa. 


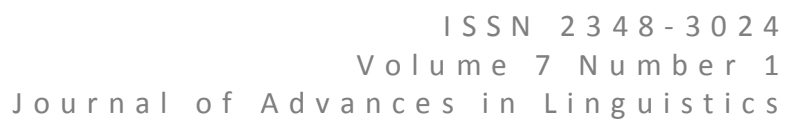

17. Levin, B. (1993). English Verb Classes and Alternations: A Preliminary Investigation. Chicago, IL: University of Chicago Press.

18. Lutrin, B. and Pincus, M. (2004). English Handbook \& Study Guide: A Comprehensive English Language Reference Book. Oxford: Heinemann Educational Publishers.

19. Lyons, J. (2002). Linguistics Semantics: An Introduction. Cambridge: Cambridge University Press.

20. Macmillan, J. H. \& Schumacher, S. (1984). Research in Education: A Conceptual Introduction. Boston, MA: Little Brown.

21. Maslow, A. (1954). Motivation and Personality. New York: Harper and Row Publishers.

22. Maslow, A. (1943). A theory of human motivation. Psychological Review 50.4: 370-396.

23. Matthew, P. H. (2007). Concise dictionary of linguistics. Oxford: Oxford University Press.

24. Moore, M. G. (1991). Editorial: Distance education theory. The American Journal of Distance Education 5.3: 1-6

25. Ogden, C. K. \& Richards, I. A. (1962). The Meaning of Meaning. New York: Harcourt, Brace.

26. Oppong-Asare, J. (2012). The Semantics of the Akan Verb 'di'. Unpublished M.Phil. Dissertation, University of Cape Coast, Cape Coast.

27. Palmer, F. R. (2004). Semantics ( $2^{\text {nd }}$ edition). Cambridge: Cambridge University Press.

28. Parent, K. (2009). Polysemy: A Second Language Pedagogical Concern. Unpublished PhD Dissertation, University of Wellington, Victoria.

29. Pavlov, I. P. (1927). Conditioned Reflexes: An Investigation of the Physiological Activity of the Cerebral Cortex. New York: Dover

30. Pustejovsky, J. (1995). The Generative Lexicon: Language, Speech, and Communication Series. Cambridge, MA: MIT Press.

31. Robert, P. (2008). Le nouveau petit Robert dictionaire alphabetique et analogique de la langue Francaise. Paris: SEJER.

32. Sarpong, S. (2005). Cases of Akan Grammaticalization: M.Phil. Dissertation submitted to the University of Education, Winneba.

33. Sekyi-Baidoo, Y. (2006). The Akan phrasal verb as a syntactic manifestation. Studies in Languages and Literature 1(2), 1-18.

34. Sekyi-Baidoo, Y. (2002). Semantics: An Introduction. Kumasi: Wilas Press Ltd.

35. Sinclair, J. (2009). The Cobuild Advanced Dictionary. Glasgow: HarperCollins Publishers.

36. Skinner, B. F. (1938). The Behavior of Organisms. New York: Appleton-Century-Crof

\section{Author' biography with Photo}

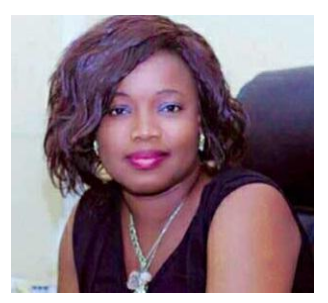

Ms. Juliet Oppong-Asare is an Assistant Lecturer at Kwame Nkrumah University of Science and Technology in the Department of Modern Languages. Her research interests include Pragmatics, Semantics, and Interlinguistics.

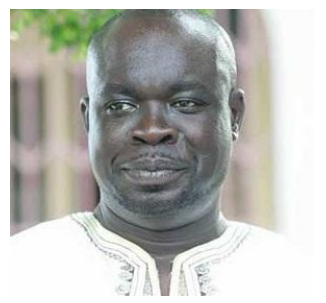

Dr. Charles Ofosu Marfo is a Senior Lecturer at the Kwame Nkrumah University of Science and Technology (KNUST) in Kumasi. He is and currently the Head of the Department of Modern Languages. He is also the current President of Linguistics Association of Ghana (LAG) and Vice Preseident of the KNUST branch of the University Teachers' Association of Ghana (UTAG). Dr. Marfo enjoys teaching and does research on various aspects of language, linguistics and communication.

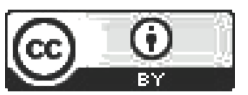

This work is licensed under a Creative Commons Attribution 4.0 International License.

DOI : $10.24297 /$ jal.v7i1.4610 